\title{
Fire-Detectors Review and Design of an Automated, Quick Responsive Fire-Alarm System Based on SMS
}

\author{
Omar Asif ${ }^{*}$, Md. Belayat Hossain², Mamun Hasan², Mir Toufikur Rahman³, \\ Muhammad E. H. Chowdhury ${ }^{4}$ \\ ${ }^{1}$ Department of EEE, Atish Dipankar University of Science \& Technology, Dhaka, Bangladesh \\ ${ }^{2}$ Department of ETE, Atish Dipankar University of Science \& Technology, Dhaka, Bangladesh \\ ${ }^{3}$ Department of EEE, University of Asia Pacific, Dhaka, Bangladesh \\ ${ }^{4}$ Department of APECE, University of Dhaka, Dhaka, Bangladesh \\ Email: saurov59@iut-dhaka.edu
}

Received 6 July 2014; revised 6 August 2014; accepted 28 August 2014

Copyright (C) 2014 by authors and Scientific Research Publishing Inc.

This work is licensed under the Creative Commons Attribution International License (CC BY). http://creativecommons.org/licenses/by/4.0/

(c) (i) Open Access

\begin{abstract}
In this work a review of existing fire-detector types has been carried out along with the development of a low cost, portable, and reliable microcontroller based automated fire alarm system for remotely alerting any fire incidents in household or industrial premises. The aim of the system designed is to alert the distant property-owner efficiently and quickly by sending short message (SMS) via GSM network. A Linear integrated temperature sensor detects temperature beyond preset value whereas semiconductor type sensor detects presence of smoke or gas from fire hazards. The sensor units are connected via common data line to ATMega8L AVR microcontroller. A SIM300CZ GSM kit based network module, capable of operating in standard GSM bands, has been used to send alert messages. The system is implemented on printed circuit board (PCB) and tested under different experimental conditions to evaluate its performances.
\end{abstract}

\section{Keywords}

Fire-Detector, Microcontroller, Fire Alarm, Temperature Sensor, SMS, GSM Network

\section{Introduction}

With the advancement of human civilization, fire-safety has been a prime concern. Fire hazards can be fatal and ${ }^{*}$ Corresponding author.

How to cite this paper: Asif, O., Hossain, Md.B., Hasan, M., Rahman, M.T. and Chowdhury, M.E.H. (2014) Fire-Detectors Review and Design of an Automated, Quick Responsive Fire-Alarm System Based on SMS. Int. J. Communications, Network and System Sciences, 7, 386-395. http://dx.doi.org/10.4236/ijcns.2014.79040 
denigrating for industrial and household security, also minatory for human life. The best way to reduce these losses is to respond to the emergency situation as quick as possible. So, there comes the necessity of standalone autonomous fire detection systems. These systems render the works of quick detection, alarm notification, and sometimes initiation of fire extinguishing. The systems, equipped with smoke, temperature, pyro-electric sensors can detect unfavourable accidental situations, as it happens, and with the help of a processing unit can alert instantly for undertaking cautious measures. In these fatal situations, early detection and faster alert will yield lesser losses of property and life.

A fire or smoke alarm system can be monitored locally in the premises, or remotely at a distant place as per requirement. Remote alarm system provides the owner of the premise with the advantage of monitoring from distant location and taking immediate actions when an emergency message is received, unlike a manual system. Remote monitoring systems can be designed in various ways-using wireless sensor networks, Ethernet, image processing and other digital communication technologies [1]-[3]. Although the systems are reliable and have a wide range of pros, they are accompanied by concerns about being complex, uncompact, non-standalone, expensive and having redundant appurtenances. Therefore, there is necessity for a system which would be reliable and swift responsive as well as simple, easy implementable and cost effective.

Fire hazards cause woebegone incidents throughout the world, especially in the developing countries where the fire-safety measures are precarious and often inadequate. Bangladesh, being the cynosure of industrial and household fire accidents in recent years [4] [5], particularly in Ready Made Garments section, is in dire need of tenable, reliable, and easily affordable fire security system which would be cost effective as well. Although a number of advanced systems are used in practical scenarios, a reliable, easy implementable and cost-effective automated fire-alarm system is not available in developing countries. Therefore in this work, a review of existing fire-detectors is done, and then using one of those detectors a low cost and quick-responsive fire/smoke detection and alarm system has been designed and implemented. The system is capable of sending alert messages via GSM network and activating siren at the premises.

\section{Fire Detectors Review}

Fire detectors can be of different types with various specific features depending upon different scenarios and demands. More or less these detectors can be categorized as heat or thermal detectors, smoke or gas detectors, semiconductor gas detectors, and flame detectors [6] [7].

\subsection{Heat or Thermal Type Detectors}

Heat or thermal type detectors are the most primitive types of autonomous fire detectors, dating back to mid1800's [7]. Most of these detectors are fixed temperature ones, which activates upon reaching a predefined temperature. Others include types, which activate whenever there is an abnormal rise in temperature in the premises. Thermal detectors are reliable, inexpensive, easy to maintain, and have lower false alarm rate. But these detectors are slow, and by the time they reach predefined detection point, damage could already been underway. Therefore these detectors are of limited use.

\subsection{Smoke or Gas Detectors}

Smoke or gas detectors, a relatively newer invention, became widespread during 1970's and 1980's.These detectors usually detect fire in early flaming or smoldering stages. These detectors can be of different types having different operation principles, namely - optical or photoelectric detectors, ionization detectors, air sampling detectors etc. [6]-[8]. Each of these types has specific applications in specific circumstances.

Photoelectric or optical smoke detectors include various components, mainly, a light source (usually an infrared LED), and a lens to converge light rays into a beam, and a photodiode [6]. In normal condition, the light beam passes straight. But whenever smoke interrupts the path of light, scatters fraction of light into the photodiode, the smoke detector is activated. This method of detection can detect fires that begin with long duration of smoldering aptly [9]. Ionization smoke detectors are based on ionization from radioactive elements like americium-241. This radioactive isotope emits alpha particles into an ionization chamber, which comprises of electrodes. The alpha particles ionize the air inside the chamber, resulting current flow between the electrodes. Now, whenever smoke particles from a nearby fire passes through the chamber, the ions get attached to smoke parti- 
cles, and thereby interrupts the current flow between the electrodes, and activates the detector [6]. This type of detectors is more suited to rapid flaming fire outbursts, unlike the photoelectric detectors, which responds better to smoldering stages [9]. Ionization detectors might perform better where there is risk of fast flaming fire, whereas photoelectric detectors react better to cases of slow smoldering, like electrical or furnishing fire. Ionization devices are weaker in scenarios where air-flow is high. Although ionization type detectors are cheaper than photoelectric ones, they have more chance of false alarm than the photoelectric detectors [10]. However, ionization based detectors have safety issues and possess threats to environment, because of americium-241. Therefore, on the basis of performance and safety concern some countries have banned ionization based alarms, and different fire authorities and associations have reports not recommending use of these detectors [6]. Air sampling detectors have applications in very sensitive areas, as they can detect very fine smoke particles. These detectors are mostly air aspirating type systems. Generally they comprise a control unit, and a network of sampling tubes or pipes. The control unit consists of detection chamber, an aspiration fan, and necessary operation circuitry. Since this type of detectors are very sensitive and fast responding, they have applications in high-value and critical areas, such as, aesthetic galleries, archives, vaults, server rooms, high-tech organizations etc. However, these detection systems are complex and expensive.

Moreover, some combination smoke alarms include both ionization and photoelectric technologies in a single device. Some smoke alarms use a carbon dioxide sensor or carbon monoxide sensor for detection as well [6].

\subsection{Flame Type Detectors}

Flame type detectors are sophisticated equipment to detect the flame phenomena of a fire. These detectors have various types depending on the light wavelength they use. Such as, ultraviolet, near infrared, infrared, and combination of UV/IR type detectors.

UV detectors generally work with wavelengths shorter than $300 \mathrm{~nm}$. This type of detectors can detect fires and explosions situations within 3 - 4 milliseconds from the UV radiation emitted from the incident. However, to reduce false alarm triggered by UV sources such as lightning, arc welding etc. a time delay is often included in the UV flame detector. The near Infrared sensor or visual flame detectors work with wavelengths between 0.7 to $1.1 \mu \mathrm{m}$. One of the most reliable technologies available for fire detection, namely multiple channel or pixel array sensors, monitors flames in the near IR band. The Infrared (IR) flame detectors work within the infrared spectral band (700 nm - $1 \mathrm{~mm})$. Usual response time of these detectors is $3-5$ seconds. Also, there is UV and IR combined flame detectors, which compare the threshold signal in two ranges to detect fire and minimize false alarms [11] [12].

Flame detectors are expensive and complex, though they provide very reliable and accurate response. They can operate in highly sensitive environment where other detectors can't be used. Aircraft maintenance facilities, fuel loading platforms, mines, refineries, high-tech industries etc. use these flame detectors for safety [7].

\subsection{Semiconductor Gas or Smoke Detectors}

These work by the principle of chemical reaction taking place between gas from fire incident and semiconductor material present inside the sensor (Figure 1). The semiconductor material used in these sensors is metal oxides, generally Tin dioxide $\left(\mathrm{SnO}_{2}\right)$, Tungsten oxide $\left(\mathrm{WO}_{3}\right)$, etc. Under normal circumstances, the surface potential acts as a potential barrier to restrict electron flow within the sensor circuitry. However, the deoxidizing gases from fire incidents diminish the oxygen surface density, and thereby reduce barrier potential to permit electron flow. The associated electrical circuitry detects the rise in conductivity due to electron flow, and activates alarm to undertake necessary measures [13].

These semiconductor sensors have wide range of applications for their advantageous features. They are small, compact, inexpensive, easy to install and maintain. These metal oxide type detectors are aptly used to detect fire incidents involving combustible gas, LP gas, methane, propane, alcohol, carbon monoxide etc. for their reliability. These features make this detector best suited for our purpose and hence we opted for it in our system.

\section{Design of Fire-Alarm System}

Figure 2 depicts the proposed fire alarm system where multiple sensor units (each comprising smoke/gas and temperature detectors) are placed inside the arena which has fire safety concerns. All the sensors are connected 


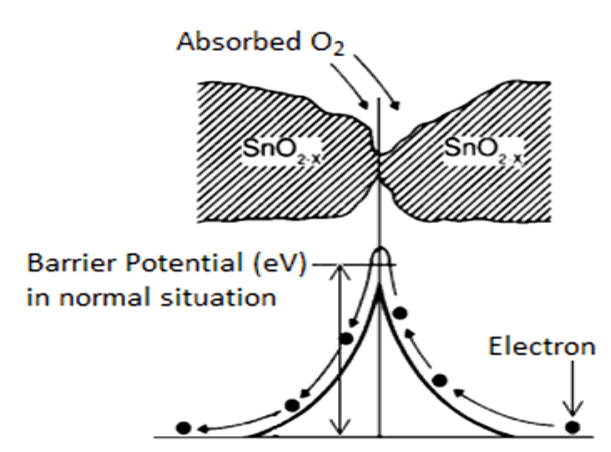

(a)

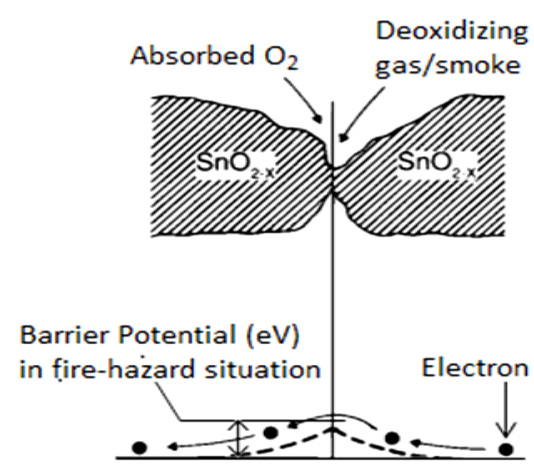

(b)

Figure 1. Working principle of semiconductor sensor (a) higher barrier potential restricts electron flow (b) reduced barrier potential permits electron flow resulting rise in sensor conductivity [13].

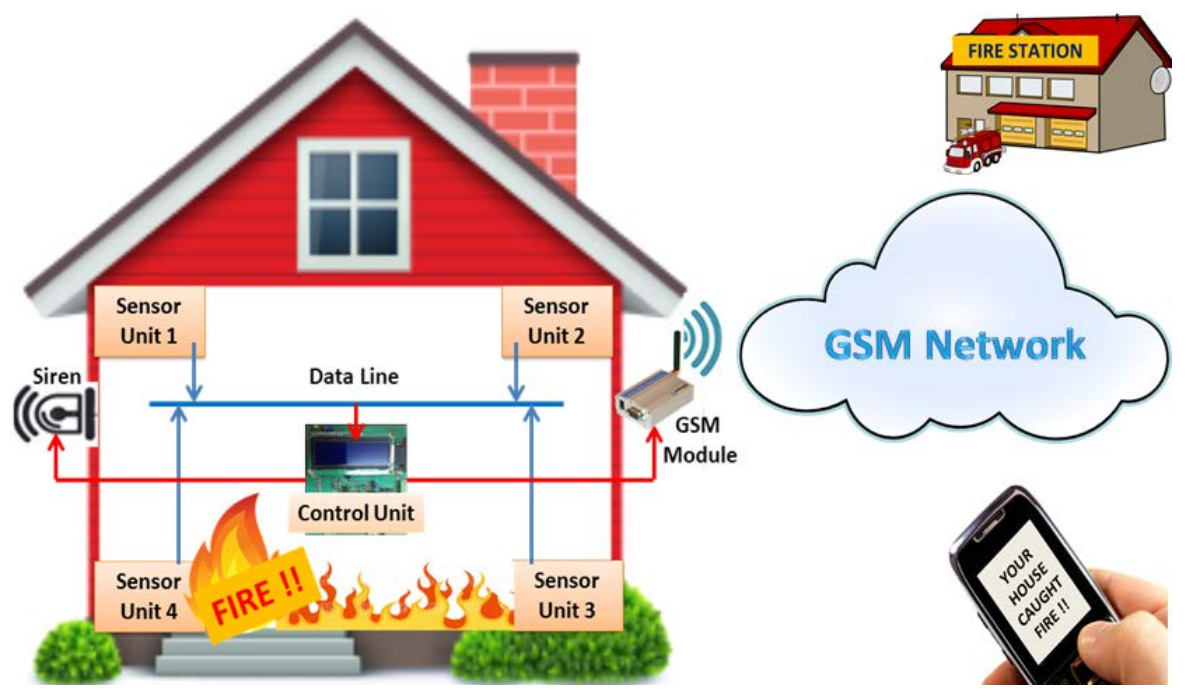

Figure 2. Overview of the System.

via a data input line to the control unit. So whenever any of the sensors detects any anomaly, the control unit starts its action. It activates the local siren and the GSM module. Thereby, an alarm message in the format of Short Message Service (SMS) will be rendered at the same time through the GSM network to the authority and the fire station nearby.

\subsection{Hardware Design}

The hardware of the system mainly comprises sensor section, control unit, network module, and power supply.

\subsubsection{Sensor Section}

It comprises of a smoke/gas, temperature sensors, comparators and variable resistors. MQ2 is a semiconductor typesensor (ref. Section 2.4), which can aptly sense presence of smoke, LPG, methane, butane, propane and other hydrocarbon combustible gases. The sensitive material in this sensor is Tin dioxide $\left(\mathrm{SnO}_{2}\right)$. When comes in contact with the gas to be monitored, the electrical resistance of the sensor decreases, enabling the microcontroller to respond to the situation. The analog voltage from the sensor is applied to the input of the comparator IC LT1013 while its reference input voltage comes from a variable resistor to adjust the sensing intensity (Figure 3). The output of comparator has been connected to the MCU via single data line. In case of detection of smoke or gas, the output will be high, and the indicator LED will glow.

The LM35 temperature sensor is an integrated circuit sensor. Here the output voltage is linearly proportional 


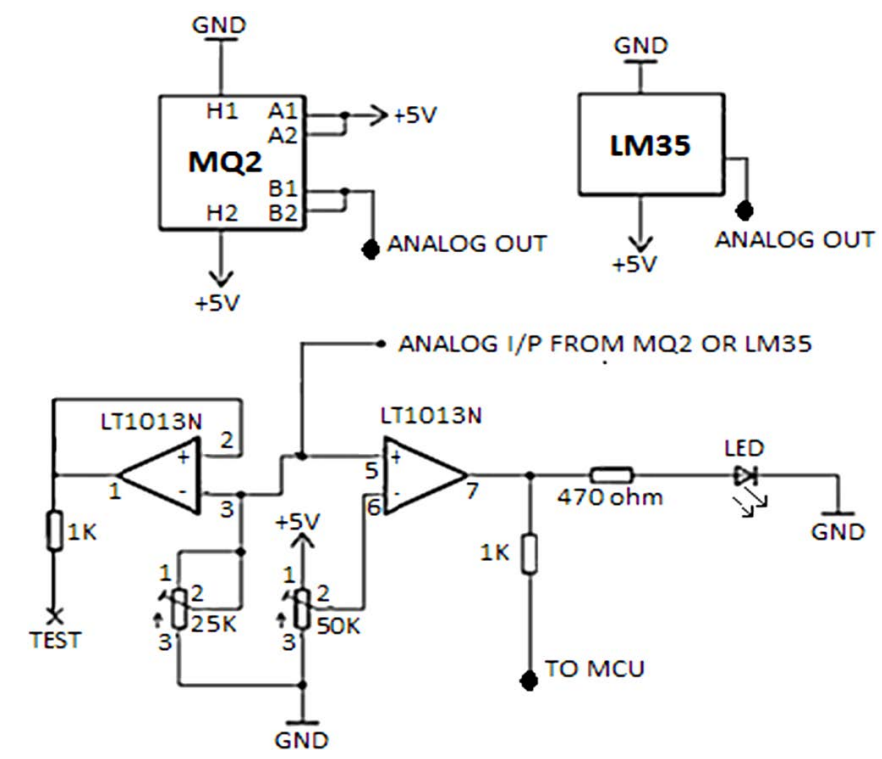

Figure 3. Circuit diagram of the sensor module.

to temperature in centigrade, making the sensor perfectly suitable for our purpose. The sensor is precise up to $\pm 1 / 4^{\circ} \mathrm{C}$ at room temperature with operation range from $-55^{\circ} \mathrm{C}$ to $150^{\circ} \mathrm{C}$, and is very low self-heating as it draws very small amount of current. The output of LM35 module is also an analog voltage (Figure 3). The circuit operation of this module is similar to the smoke detection process described above. The reference voltage of the comparator is adjusted to $500 \mathrm{mV}$ using a variable resistor same as the one used in smoke sensor circuitry. The LM35 increases its output by $10 \mathrm{mV} /{ }^{\circ} \mathrm{C}$ at the non-inverting pin of the op-amp. So when the temperature is greater than the pre-set temperature $\left(50^{\circ} \mathrm{C}\right)$, the module will make its output high.

For quick and efficient fire detection, multiple sensor units (each unit having a MQ2 smoke/gas and a LM35 temperature detector) have been placed in different fire vulnerable places in the premise. All sensor units are connected to a single I/O digital pin of the control unit via a single data line. A signal diode has been used in each sensor unit to protect other un-triggered sensor units from reverse current. This type of connection has the advantage of providing multiple sensor connection compatibility covering a considerably large area; only using a single microcontroller and avoiding the necessity of multi-channel ADC chip, also saving I/O pins for additional features. Any MQ2 and/or LM35 sensor unit will trigger the data bus to logic high state (5 V) if any smoke or gas is present in the location, or if room temperature surpasses the preset value due to fire or any other accidental situation.

\subsubsection{Control Unit}

The heart of the control unit is ATMega8L, a low power Atmel 8-bit AVR RISC-based general purpose computer [14]. Optimized power consumptions, good processing speed, small physical dimensions, and lower costs make this microcontroller a perfect fit for our purpose. Only one of the digital I/O pins has been used to acquire the status of the sensor units via common data line. A Liquid Crystal Display (LCD) has been interfaced to the controller to show the status of the system. The controller also operates a piezo type siren via a $12 \mathrm{~V}$ relay to alert the local authority about fire-hazard. RS 232 Serial communication protocol has been used to control the GSM module using AT commands (Table 1). A DB9 serial port has also been connected to the microcontroller for firmware update (Figure 4).

\subsubsection{Network Module}

The alert message can be sent to distant remote locations using various means like: wireless networks (RF Tx/Rx pair), wireless sensor network, Ethernet, GSM network etc. Among these, GSM based mobile network is most feasible for its availability all over the globe and cost-effectiveness.

GSM module requires a Subscriber Identification Module (SIM) card from a wireless carrier to operate. To control the module and process short messages AT commands are required, which are defined in the GSM stan- 
Table 1. List of AT commands used in the system.

\begin{tabular}{cc}
\hline Commands & Description \\
\hline AT & Status \\
AT + CREG? & Network registration \\
AT + CIMI & Request international mobile subscriber identity \\
AT + CPBF & Find phonebook entries \\
AT + CMGF & Select SMS message format \\
AT + CMGS & Send SMS message \\
\hline
\end{tabular}

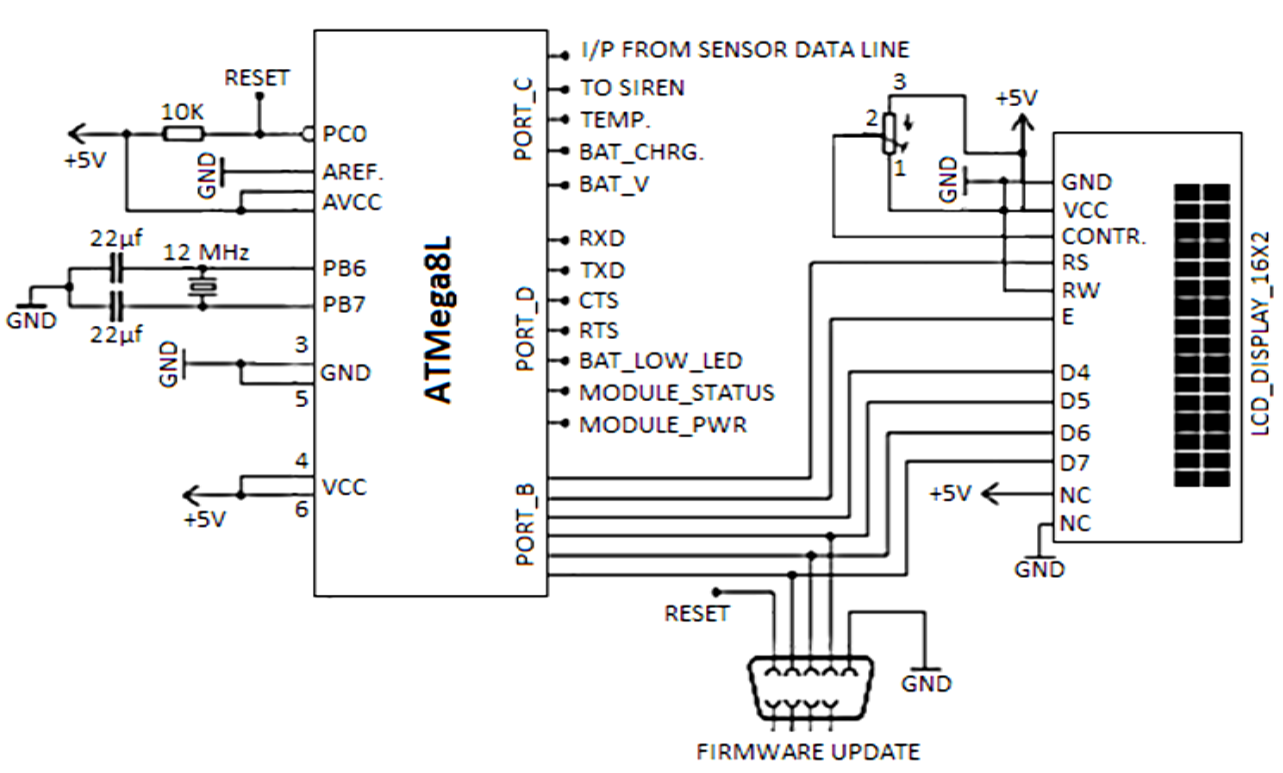

Figure 4. Sensors connection scheme to the controller.

dards. In the present work, a SIM300CZ GSM kit has been used [15]. The network module has been shown in the Figure 5. It operates on the $850 / 1900 \mathrm{MHz}$ and $900 / 1900 \mathrm{MHz}$ frequency bands, which is available throughout the globe. SIM interface to the GSM kit have been designed and implemented in printed circuit board. This type of design offers low power consumption as the network module operates at $5 \mathrm{~V}$ and reduces cost of the system as there are no communication interface circuitries (i.e. RS 232 level translator).

\subsubsection{Power Supply}

A 12 Volt Li-Ion Rechargeable battery ensures uninterrupted power supply to the entire system. A LM7805 voltage regulator regulates the voltage at $5 \mathrm{~V}$ to power up the microcontroller and sensor units. The battery is charged by AC power, under the control of a charger controller. Battery charge level is monitored by applying a reference voltage to an ADC channel of the MCU. A voltage divider and a Zener diode are used to keep the reference voltage level between $0-5 \mathrm{~V}$. A pair of green and red LEDs indicates the charging and battery low status of the system respectively. If the battery voltage is less than $10.5 \mathrm{v}$, the red LED flashes. So, the battery would have to be charged, flashing the green LED.

\subsection{Software Design}

The whole system is controlled by a firmware which is implemented in embedded $\mathrm{C}$ and built in mikroC compiler [16]. Then the program is downloaded to the 8-bit Atmega8L microcontroller. Figure 6 shows the Program Flowchart. It includes developing algorithm for the system, allocating memory blocks as per functionality, writing the separate routines for different interfacing devices, and finally testing them on the developed hardware. 


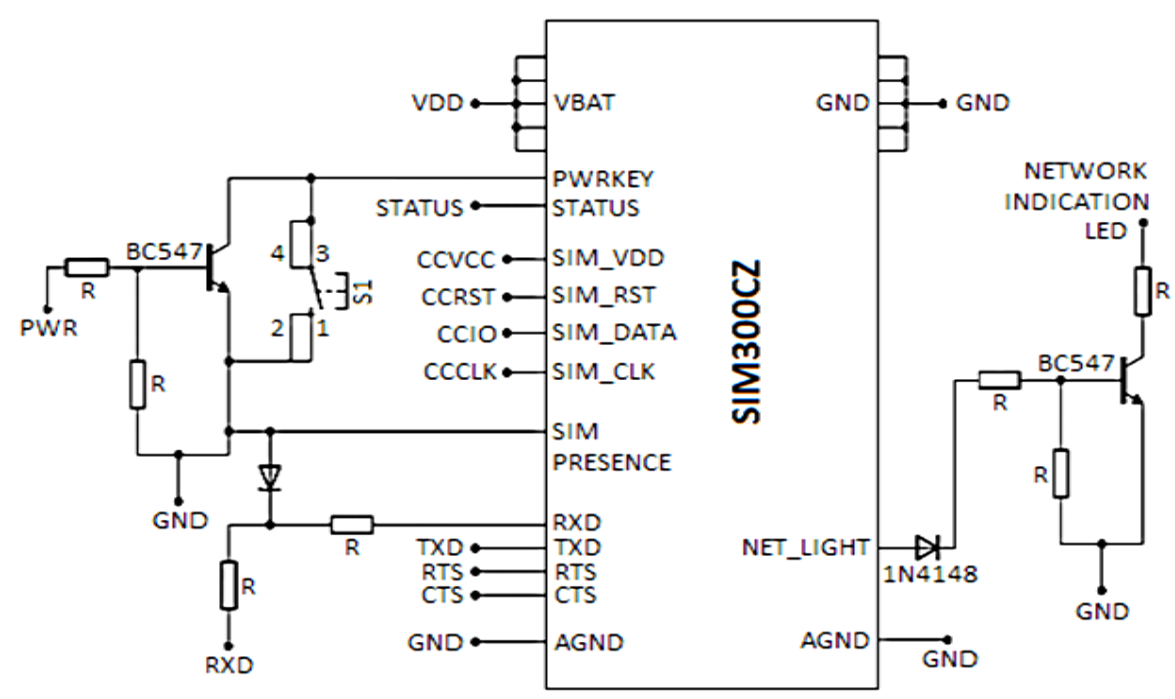

Figure 5. Circuit diagram of GSM Module.

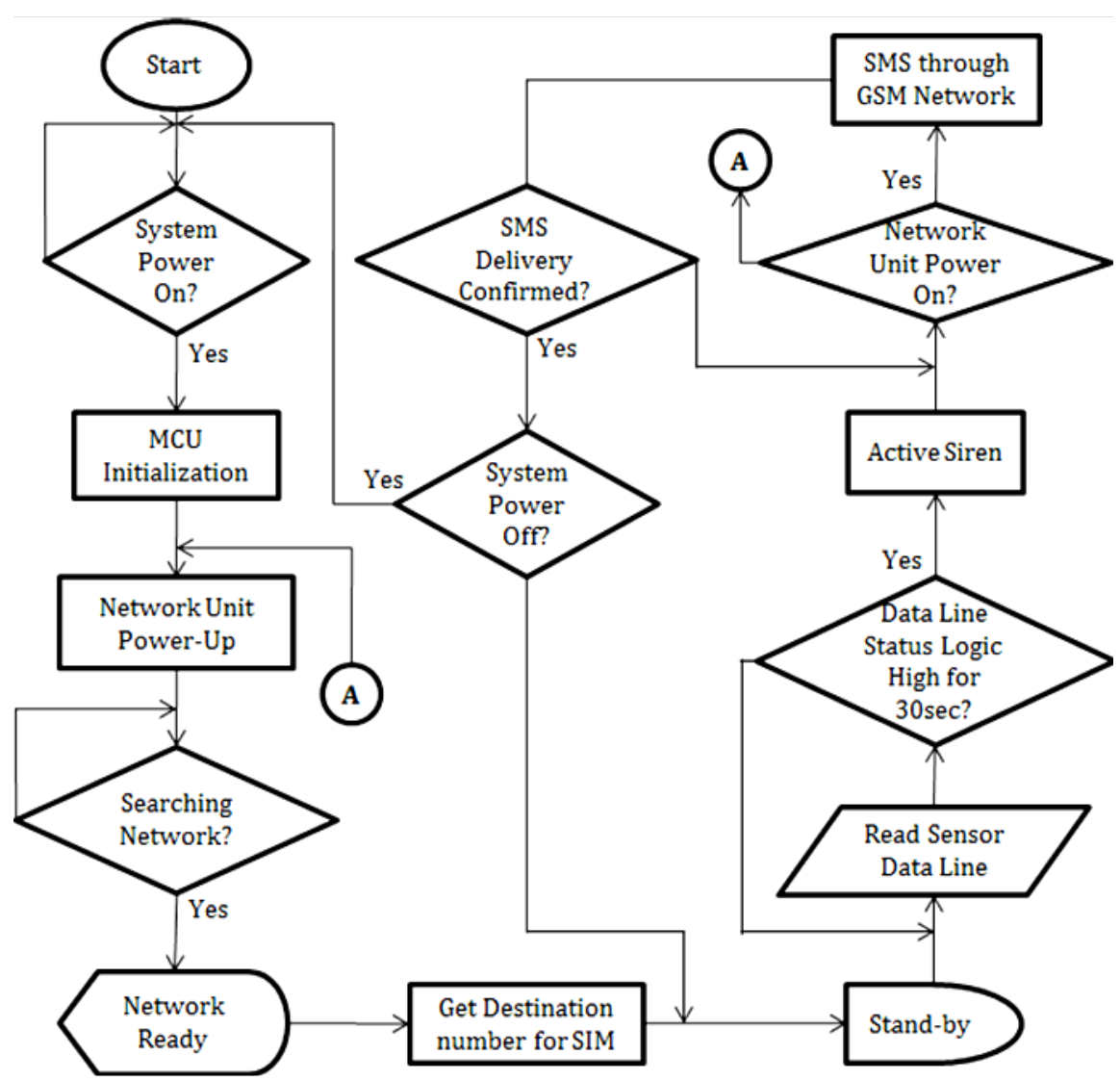

Figure 6. Flow code of the system program.

\section{Hardware Implementation}

EAGLE printed circuit board (PCB) software V.6.0 from CadSoft Computer [17] has been used for designing two separate single layers and one double layer PCB layout. The single layer layouts comprise the sensor modules, and the double layer layout houses the control unit and the network unit. Finally, after placing all the components on the PCB layouts, the complete implemented hardware of the system is shown in Figure 7. 


\section{Results and Discussion}

To observe the performance and response of the system to adverse fire situations, 10 individual simulation tests were performed with varying smoke, gas, and temperature conditions. The result of the tests suggests the system renders desired alert responses under different test conditions reliably. The experimental set-up of the tests is shown in Figure 8. And the system responses under varying situations of fire or smoke or gas or temperature are shown in Figure 9.

During the tests, the time taken from fire detection to alert message (SMS) delivery via GSM network by the system has been noted down as well. These time responses have been plotted in Figure 10. The maximum time taken by the system to deliver alert SMS was 10.5 seconds (test no. 9), and the minimum time was 7 seconds (test no. 1 and 6) approximately. As it is seen, on an average, the developed system takes 7 - 10 seconds to deliver alert SMS to the concerned authority, which is quick enough to undertake necessary measures to avert the fire hazard.

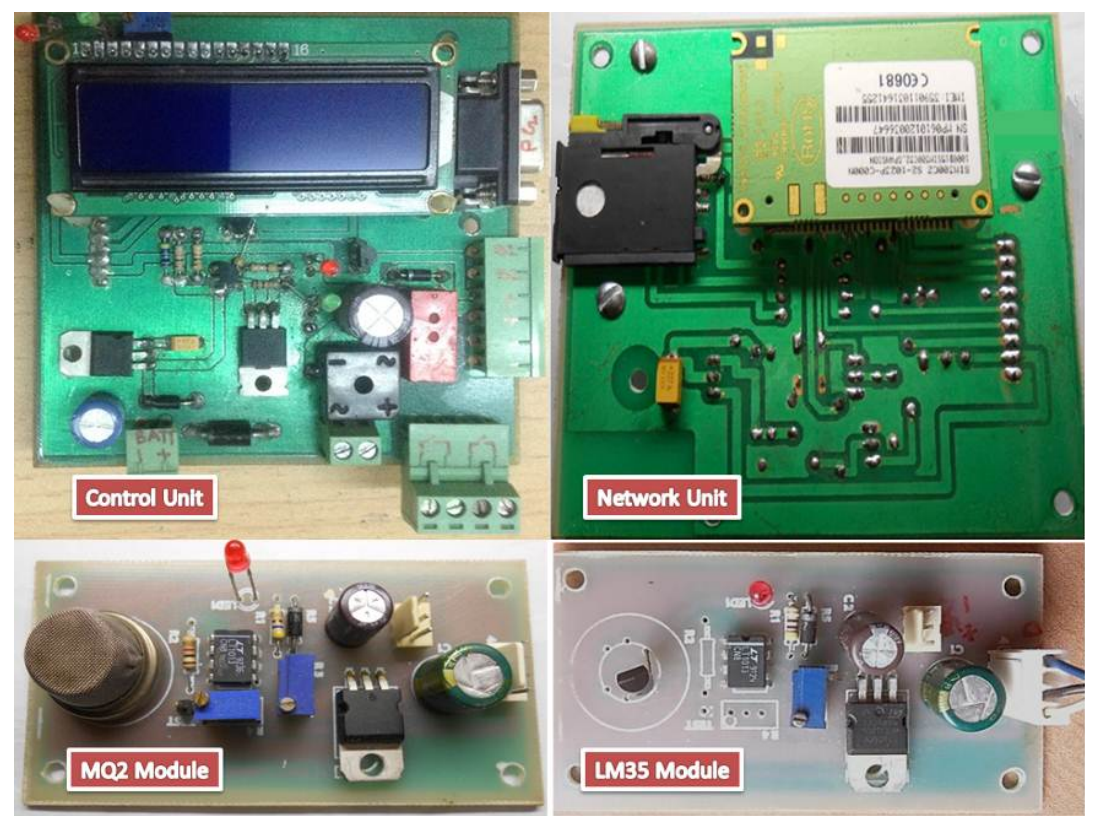

Figure 7. Snapshot of the hardware.

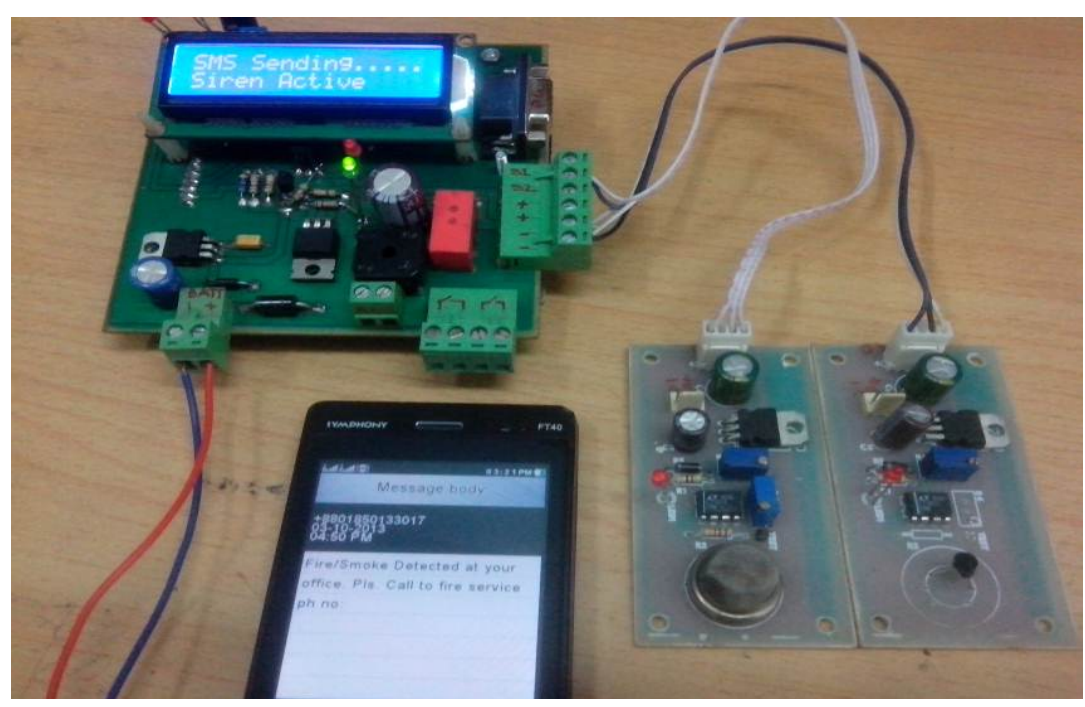

Figure 8. Testing of developed system. 


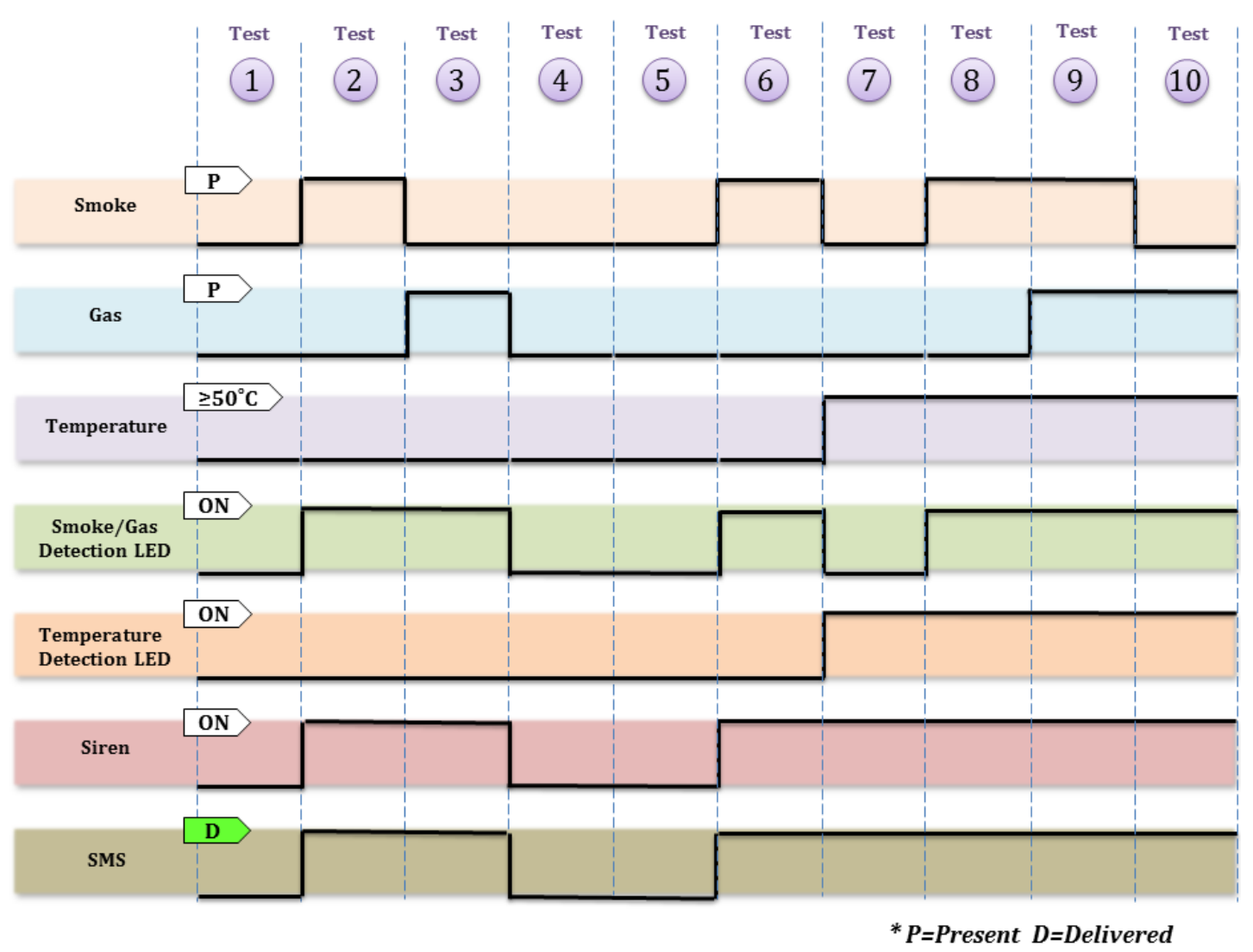

Figure 9. System performances under different situations.

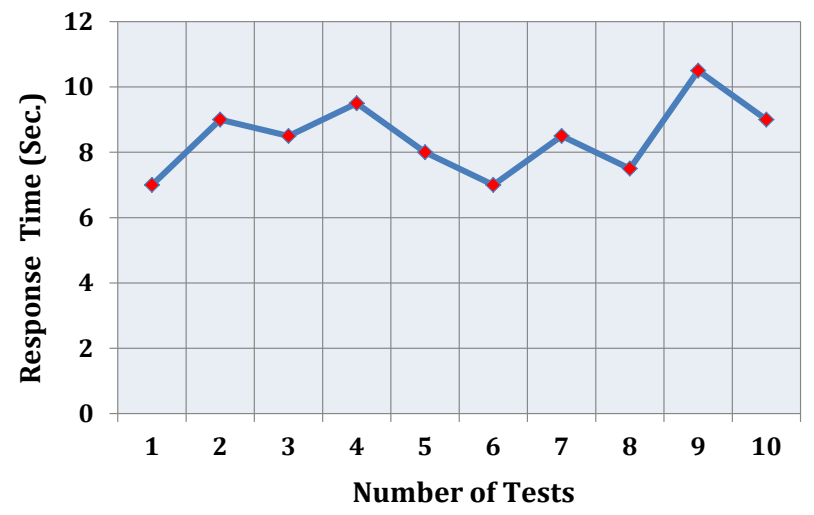

Figure 10. System response time.

\section{Conclusions and Future Scope}

The designed fire alarm system is simple but it has wide area of application in household and industrial safety, especially in developing countries. Using this system, quick and reliable alert response is possible to initiate preventive measures to avert danger of fire hazards and minimize losses of life and property. This is a cost effective fire alarm system which performs reliably to ensure safety from fire, and can be installed in houses, industries, offices, ware-houses etc. very easily. It can be used to detect burnable gas like methane, LPG etc. as well. The designed systems have coverage up to 100 square meter area by using a category- 6 cable as data line. Large industrial or residential area can be monitored through the proposed system installing multiple modules, each for one floor or unit. The system can be further developed with added features like web server interconnect, fire area tracking and fire extinguisher interfacing etc. 


\section{References}

[1] Zhang, L. and Wang, G. (2009) Design and Implementation of Automatic Fire Alarm System Based on Wireless Sensor Networks. Proceedings of the International Symposium on Information Processing (ISIP’09), Huangshan, 21-23 August 2009, 410-413.

[2] Kwon, O.H., Cho, S.M. and Hwang, S.M. (2008) Design and Implementation of Fire Detection System. Advanced Software Engineering and Its Applications, Hainan Island, 13-15 December 2008, 233-236.

[3] Li, J.H., Zou, X.H. and Lu, W. (2012) The Design and Implementation of Fire Smoke Detection System Based on FPGA. Proceedings of the 24th Control and Decision Conference, Taiyuan, 23-25 May 2012, 3919-3922.

[4] BBC NEWS ASIA (25 November 2012) Dhaka Bangladesh Clothes Factory Fire Kills more than 100. http://www.bbc.com/news/world-asia-20482273

[5] The Guardian (4 June 2010) Dhaka Fire Kills up to 150 in Bangladesh. http://www.theguardian.com/world/2010/jun/04/dhaka-fire-bangladesh

[6] Cote, A. and Bugbee, P. (1988) Ionization Smoke Detectors. Principles of Fire Protection. National Fire Protection Association, Quincy, 249.

[7] Northeast Document Conservation Center, Nick Artim, an Introduction to Fire Detection, Alarm, and Automatic Fire Sprinklers. http://www.nedcc.org/free-resources/preservation-leaflets/3.-emergency-management/3.2-an-introduction-to-fire-detect ion,-alarm,-and-automatic-fire-sprinklers

[8] Safelincs-Fire Safety Products. http://www.safelincs.co.uk/

[9] National Fire Protection Association, Ionization vs. Photoelectric. http://www.nfpa.org/safety\%20information/for\%20consumers/fire\%20and\%20safety\%20equipment/smoke\%20alarms/ ionization\%20vs\%20photoelectric.aspx

[10] Bukowski, R.W., Peacock, R.D., Averill, J.D., Cleary, T.G., Bryner, N.P., Walton, W.D., Reneke, P.A. and Kuligowski, E.D. (2007) Performance of Home Smoke Alarms Analysis of the Response of Several Available Technologies in Residential Fire Settings. NIST TN 1455-1; NIST Technical Note 1455-1; p. 396. http://fire.nist.gov/bfrlpubs/fire07/art063.html

[11] Wikipedia, the Free Encyclopedia (2013) Flame Detector. http://en.wikipedia.org/wiki/Flame_detector

[12] Wikipedia, the Free Encyclopedia (2013) Flame Detection. http://en.wikipedia.org/wiki/Flame_detection

[13] Figaro Engineering Inc. (2014) http://www.figarosensor.com/products/general.pdf

[14] Atmel (2014), ATmega8. http://www.atmel.com/devices/atmega8.aspx

[15] Micron Electronics (2014), SIM300C GSM/GPRS MODULE. http://www.simcom.us/product detail.php?cid=1\&pid=2

[16] MikroElektronika (2014) mikroC PRO for AVR. http://www.mikroe.com/mikroc/avr/

[17] CadSoft Computer (2014) CadSoft EAGLE PCB Design Software.

http://www.cadsoftusa.com/eagle-pcb-design-software/ 
Scientific Research Publishing (SCIRP) is one of the largest Open Access journal publishers. It is currently publishing more than 200 open access, online, peer-reviewed journals covering a wide range of academic disciplines. SCIRP serves the worldwide academic communities and contributes to the progress and application of science with its publication.

Other selected journals from SCIRP are listed as below. Submit your manuscript to us via either submit@scirp.org or Online Submission Portal.
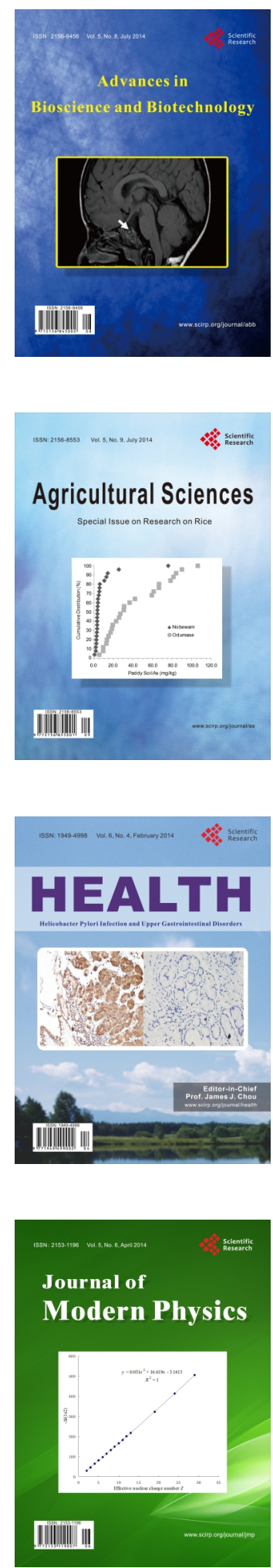
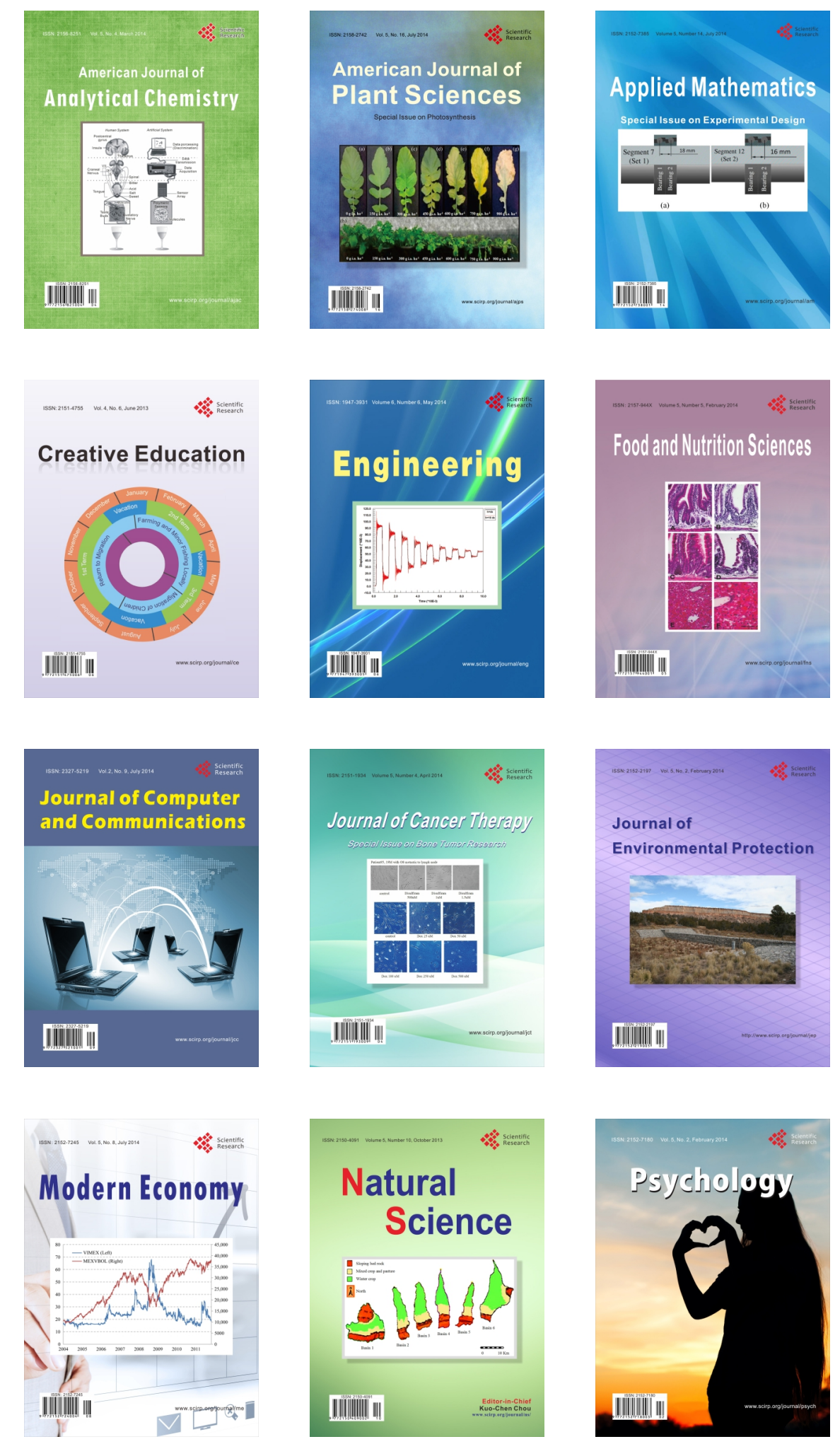